\title{
CORRIGENDUM
}

\section{Silent synapses and the emergence of a postsynaptic mechanism}

for LTP

Geoffrey A. Kerchner and Roger A. Nicoll

Nature Reviews Neuroscience 9, 813-825 (2008)

In the above article, an important reference was omitted and appropriate credit was not given for the first observation of silent synapses by laser-evoked glutamate uncaging on to single, visually identified dendritic spines. In the rat hippocampal CA1 region, Beique et al. ${ }^{1}$ observed thin spines that exhibited an NMDAR-mediated response at $+40 \mathrm{mV}$, but no AMPARmediated response at $-70 \mathrm{mV}$, a little over a year before a similar observation by Busetto et al. ${ }^{2}$.

1. Beique, J. C. et al. Synapse-specific regulation of AMPA receptor function by PSD-95. Proc. Natl Acad. Sci. USA 103, 19535-19540 (2006)

2. Busetto, G., Higley, M. J. \& Sabatini, B. L. Developmental presence and disappearance of postsynaptically silent synapses on dendritic spines of rat layer 2/3 pyramidal neurons. J. Physiol. 586, 1519-1527 (2008) 